
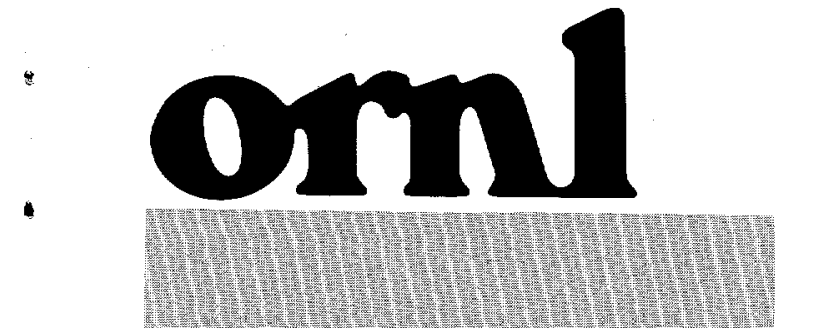

OAK RIDGE

NA NIONAL

LABORATORY
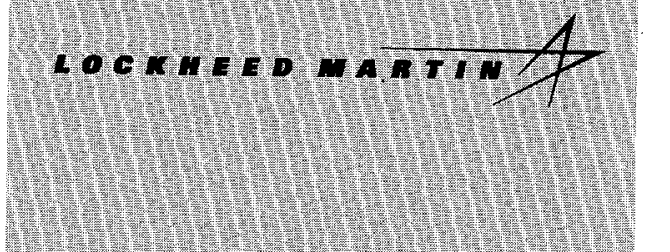

1)
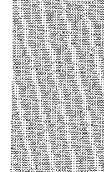

4)
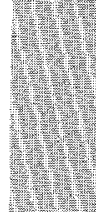


\section{DISCLAIMER}

This report was prepared as an account of work sponsored by an agency of the United States Government. Neither the United States Government nor any agency thereof, nor any of their employees, make any warranty, express or implied, or assumes any legal liability or responsibility for the accuracy, completeness, or usefulness of any information, apparatus, product, or process disclosed, or represents that its use would not infringe privately owned rights. Reference herein to any specific commercial product, process, or service by trade name, trademark, manufacturer, or otherwise does not necessarily constitute or imply its endorsement, recommendation, or favoring by the United States Government or any agency thereof. The views and opinions of authors expressed herein do not necessarily state or reflect those of the United States Government or any agency thereof. 


\section{DISCLAIMER}

Portions of this document may be illegible in electronic image products. Images are produced from the best available original document. 


\title{
HFIR VESSEL PROBABILISTIC FRACTURE ANALYSIS, CONSIDERING SUCCESS OF HYDROSTATIC PROOF TESTS
}

\author{
R. D. Cheverton \\ Delta-21 Resources, Inc.
}

Manuscript completed: January 1997

Manuscript published: January 1999

Prepared by

OAK RIDGE NATIONAL LABORATORY

Oak Ridge, Tennessee 37831-6285

managed by

LOCKHEED MARTIN ENERGY RESEARCH INC.

for the

U. S. DEPARTMENT OF ENERGY

under contract DE-AC05-96OR22464 


\section{TABLE OF CONTENTS}

Acknowledgments

Abstract

1. Introduction $\ldots \ldots \ldots \ldots \ldots \ldots \ldots \ldots \ldots \ldots \ldots \ldots \ldots$

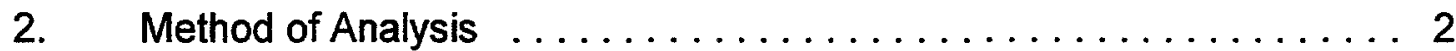

2.1 General information $\ldots \ldots \ldots \ldots \ldots \ldots \ldots \ldots \ldots \ldots$

2.2 Probability of Failure for hydro-test loading conditions . . . . . 3

2.3 Probability of failure for emergency/faulted conditions ...... 8

3. Discussion, Summary, and Conclusions $\ldots \ldots \ldots \ldots \ldots$

References ................................ 10 


\section{ACKNOWLEDGEMENTS}

The author wishes to acknowledge contributions by T. L. Dickson and S. J. Chang (helpful discussions and peer reviews) and Mary Wells (preparation of document). 


\begin{abstract}
Periodic hydrostatic proof testing and probabilistic fracture mechanics analyses are performed to demonstrate the structural integrity and useful life of the High Flux Isotope Reactor (HFIR) pressure vessel. Calculations of the hydro-test conditions (pressure, temperature, and frequency) and of the probability of failure account for vessel degradation (flaw growth and radiation-induced embrittlement) that takes place between tests and of the credible worst-case-operating condition. The specified useful life of the vessel is limited by specified maximum permissible calculated probabilities of failure for hydro-test and worst-case-operating conditions. The probability of failure can be calculated with or without accounting for the success (absence of failure) of a test, but if success is accounted for, the calculated probabilities are less and thus the maximum permissible life greater. This report describes a simple method for including the success of a test.
\end{abstract}




\section{INTRODUCTION}

The life of the High Flux Isotope Reactor (HFIR) pressure vessel is limited by a radiation-induced reduction in the fracture toughness of the vessel materials. The reduction in toughness increases the chances of a sharp crack-like defect (flaw) propagating through the vessel wall, resulting in vessel failure.

Hydrostatic proof testing and a probabilistic fracture-mechanics analysis are applied to the HFIR vessel to confirm its structural integrity and to extend its life well beyond the vessel's original design value. ${ }^{1}$ Hydro testing demonstrates that the vessel is safe to operate for the period of time between hydro tests, and the probabilistic analysis indicates whether the probability of vessel failure during the hydro test and also during emergency/faulted conditions is acceptably small. Furthermore, a successful hydro test (nonfailure of the vessel) provides information that can be included in the probabilistic analysis to reduce the calculated probability of failure.

The probability of failure of the HFIR vessel was first calculated in Ref. 1, and more recently the calculation was upgraded in connection with vessel life-extension studies. ${ }^{2,3,4}$ None of these studies, however, included the beneficial effect of successful hydro tests. The present configuration of the HFIR core and experimental facilities does not require inclusion of the beneficial effects to satisfy the related criteria. However, recent proposals for enlargement of the beam tubes ${ }^{5}$ and calculations of related increases in the dose rates in the vessel wall ${ }^{6}$ indicate that the reduction in the probability associated with application of hydro testing may need to be considered. This report discusses a method of doing that and uses the method to indicate quantitatively what the benefits might be. 


\section{METHOD OF ANALYSIS}

\subsection{General Information}

FAVOR, ${ }^{7}$ a probabilistic fracture-mechanics code based on Monte Carlo techniques, is used for calculating the conditional probability of failure $[P(F / E)]$ (conditional in the sense that it pertains to a specific loading condition) for the HFIR vessel. Many vessels are simulated by simulating parameters that significantly influence the potential for failure. A deterministic fracture-mechanics analysis is performed for each of the many simulated vessels to determine which ones fail for a particular loading condition and a particular time in the life of the vessel. The conditional probability of failure is equal to the number of vessels that are calculated to fail divided by the total number of vessels simulated. That is,

$$
P(F \mid E)=V_{F} / V_{S}
$$

where

$$
\begin{aligned}
& V_{F}=\text { number of vessels calculated to fail } \\
& V_{S}=\text { number of vessels simulated }
\end{aligned}
$$

Typically, $10^{8}$ vessels are simulated.

The number of vessels that fail, and thus $P(F / E)$, tend to increase with time because of the continuing degradation (flaw growth and radiation-induced reduction in fracture toughness) of the vessel. If the effect of periodic hydro testing is not considered in the analysis, $P(F / E)$ will increase continuously with time $(t)$, and, if flaw growth is not significant, will approach an asymptote. This is indicated in Fig. 1, which includes curves of $P(F / E)$ vs $t$ for several relative dose rates $(R)$, with $R=1$ representing the existing HFIR core/experimental-facilities design. The loading condition is that associated with the hydro-test conditions proposed for the life-extension period 26-50 EFPY(100 MW). ${ }^{3}$ 
Saturation of $P(F / E)$ eventually takes place because the radiation-induced reduction in fracture toughness approaches a maximum (fracture toughness approaches a minimum) as indicated by the following equation for fracture toughness $\left(K_{1}\right):{ }^{8}$

$$
K_{l c}=A+B \exp \left[C\left(T-R T_{N D T_{0}}-\Delta R T_{N D T}\right)\right],
$$

where

$$
\begin{array}{ll}
K_{1 c} & =\text { plain-strain static fracture toughness } \\
A, B, C & =\text { constants } \\
T & =\text { material temperature } \\
R T_{N D T_{0}} & =\text { initial value of reference nil-ductility transition temperature } \\
\Delta R T_{N D T} & =\text { increase in } R T_{N D T} \text { due to radiation exposure }
\end{array}
$$

The value of $\Delta R T_{N D T}$ increases with time, and thus $K_{1 c}$ approaches $A$ with increasing time.

Based on HFIR surveillance data, the rate of increase of $R T_{\text {NDT }}\left(\Delta R T_{N D T}\right)$ is independent of time, thus far. ${ }^{9}$ Eventually, however, $\Delta \dot{R} T_{N D T}$ will gradually decrease with exposure, ${ }^{1,10}$ and, thus, $\Delta R T_{N D T}$ will tend to approach a maximum value. This,

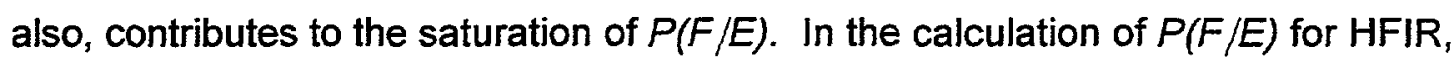
it has been assumed, conservatively, that $\triangle R T_{N D T}$ is independent of time. Thus, the abscissa in Fig. 1 can also be the product $\Delta \dot{R} T_{N D T} \times t$ where $\Delta \dot{R} T_{N D T}$ is an effective value for all regions of the vessel included in the analysis. This feature will be used later to help illustrate the effect of hydro testing on $P(F / E)$.

\subsection{Probability of Failure for Hydro-Test (HT) Loading Conditions}

Each time a hydro test is conducted successfully, $P(F / E)(H T)$ is reduced to zero. Thus, the simulated vessels that were calculated to fail do not exist; that is, the actual HFIR vessel is not represented by any one of those vessels. Thus, these vessels 
can be subtracted from the number of failed vessels. This results in $P(F / E)(H T)=0$ for the time of the hydro test and reduced values of $P(F / E)(H T)$ for all later times (each point on the curve represents the accumulated number of failed vessels up to the time corresponding to the point). To illustrate, suppose, with reference to Fig. 2, in which curve $A$ is the same as the $R=1$ curve in Fig. 1 , that the first hydro test is conducted at 26 EFPY $(100 \mathrm{MW})$, and thereafter they are conducted every 3.0 EFPY (100 MW). Following the first test, $P(F / E)(H T)$ increases from zero, tracking curve $B$, which is curve $A$ minus $P(F / E)(H T, t=26)=5.0 \times 10^{-7}$. At the time of the next hydro test $(t=29)$, but before the test is conducted,

$$
\begin{aligned}
P(F \mid E)(H T) & =P(F \mid E)(H T)_{\max }=8.1 \times 10^{-7}(\text { curve } A)-5.0 \times 10^{-7} \\
& \left.=3.1 \times 10^{-7} \text { (curve } B\right) .
\end{aligned}
$$

The second hydro test, if successful, once again reduces $P(F / E)(H T)$ to zero. Thus, $3.1 \times 10^{-7}$ represents the second batch of vessels that did not fail, and this batch must be subtracted from curve $B$ to obtain curve $C$; that is,

$$
\text { Curve } C=\text { Curve } A-5.0 \times 10^{-7}-3.1 \times 10^{-7} \text {. }
$$

Thus, at the time of the third hydro test $(t=32)$,

$$
\begin{aligned}
P(F \mid E)(H T)_{\max } & =12.5 \times 10^{-7}(\text { curve } A)-5.0 \times 10^{-7}-3.1 \times 10^{-7} \\
& =4.4 \times 10^{-7}(\text { curve } C) .
\end{aligned}
$$

Thus, in general,

$$
\begin{aligned}
P(F \mid E)(H T)_{\max , n} & =P(F \mid E)(H T)_{n}-\sum_{i=1}^{i=n-1} P(F \mid E)(H T)_{\max , i}, \\
& =P(F \mid E)(H T)_{n}-P(F \mid E)(H T)_{n-1},
\end{aligned}
$$


where

$P(F / E)(H T)_{\max , n}=P(F / E)(H T)$, as modified by previous hydro tests, at time of, but prior to, the $n^{\text {th }}$ hydro test.

$P(F / E)(H T)_{n} \quad=P(F / E)(H T)$, unmodified, at time of $n^{\text {th }}$ hydro test.

$P(F / E)(H T)_{\max , i}=P(F / E)(H T)$, as modified by previous hydro tests, at time of, but prior to, $\mathrm{i}^{\text {th }}$ hydro test.

It is of interest to note that $P(F / E)(H T)_{\text {max, } n}$ is a function only of $P(F / E)(H T)_{n}$ and $P(F / E)(H T)_{n-1}$ and thus is not a function of earlier hydro testing or lack thereof.

If the analytical process is carried out to the time of the last hydro test [47 EFPY $(100$ $M W)$, if the vessel lifetime is specified as 50 EFPY(100 MW), and $\Delta t=3]$, the inclusion of the hydro-test effect reduces $P(F / E)(H T)_{\max }$ from $6.0 \times 10^{-6}$ (curve $A$ ) to $1.25 \times 10^{-6}$ $\left[6.0 \times 10^{-6}\right.$ (curve $A, t=47$ ) $-4.75 \times 10^{-6}$ (curve $\left.\left.A, t=44\right)\right]$, a factor of 4.8 .

If the time between hydro tests $(\Delta t)$ is reduced, the last test occurs later, and the factor is greater $[7.3(\Delta t=2)$ and $15.3(\Delta t=1)]$. Thus, increasing the frequency of hydro testing reduces the calculated probability of failure.

The time between hydro tests can be specified to vary with time so as to achieve a desired $P(F / E)(H T)_{\max }=f(t)$. For instance, by decreasing $\Delta t$ with time in a specific manner, it is possible for $P(F / E)_{\max } \neq f(t)$. This condition is achieved by selecting values of $\Delta t$ such that the number of vesseis that fail during $\Delta t$ is the same for each value of $\Delta t$. As indicated in Table 1, this can result in decreasing values of $\Delta t$ with time.

A constant value of $P(F / E)(H T)_{\max }$ might be useful if criteria pertaining to the calculated probability of failure include a maximum permissible value of $P(F / E)$. Suppose, however, that the criteria for HFIR included maximum permissible values of the frequency of failure $[\phi(F)]$, where 


$$
\phi(F)=\phi(E) \times P(F \mid E)
$$

and

$$
\phi(E)=\text { frequency of event. }
$$

Table 1. Values of $t(H T)$ corresponding to $P(F / E)(H T)_{\max , n} \leq 5.0 \times 10^{-7}$ for $\Delta t \leq$

\begin{tabular}{|c|c|c|c|c|}
\hline \multirow[b]{2}{*}{$n$} & \multirow{2}{*}{$\begin{array}{c}P(F / E)(H T)_{n} \\
10^{-6}\end{array}$} & \multirow{2}{*}{$\begin{array}{c}P(F / E)(H T)_{\max , n} \\
10^{-6}\end{array}$} & $t(H T)$ & $\Delta t^{c}$ \\
\hline & & & \multicolumn{2}{|c|}{ EFPY(100 MW) } \\
\hline 1 & 0.50 & 0.50 & 26.0 & - \\
\hline 2 & 0.80 & 0.30 & 29.0 & 3.0 \\
\hline 3 & 1.23 & 0.43 & 32.0 & 3.0 \\
\hline 4 & 1.73 & 0.50 & 34.6 & 2.6 \\
\hline 5 & 2.23 & 0.50 & 36.8 & 2.2 \\
\hline 6 & 2.73 & 0.50 & 38.7 & 1.9 \\
\hline 7 & 3.23 & 0.50 & 40.3 & 1.6 \\
\hline 8 & 3.73 & 0.50 & 41.7 & 1.4 \\
\hline 9 & 4.23 & 0.50 & 43.0 & 1.3 \\
\hline 10 & 4.73 & 0.50 & 44.2 & 1.2 \\
\hline 11 & 5.23 & 0.50 & 45.3 & 1.1 \\
\hline 12 & 5.73 & 0.50 & 46.4 & 1.1 \\
\hline 13 & 6.23 & 0.50 & 47.5 & 1.1 \\
\hline 14 & 6.73 & 0.50 & 48.5 & 1.0 \\
\hline 15 & 7.23 & 0.50 & 49.5 & 1.0 \\
\hline
\end{tabular}
3.0 EFPY $(100 \mathrm{MW}), p(H T)^{\mathrm{a}}=850 \mathrm{psi}, T_{v}(H T)^{b}=85^{\circ} \mathrm{F}, 26 \leq t(H T) \leq 50$.

${ }^{\mathrm{a}} \mathrm{p}(H T)=$ hydro-test pressure.

${ }^{\mathrm{b}} T_{\mathrm{v}}(H T)=$ hydro-test temperature.

${ }^{\mathrm{c}} \Delta t=t\left(H T_{n}-t(H T)_{n-1} ; \Delta t_{\max }=3.0 \operatorname{EFPY}(100 \mathrm{MW})\right.$ specified. 
For the hydro-test event

$$
\phi(E)=1 / \Delta t,
$$

and thus,

$$
\phi(F)(H T)=P(F \mid E) / \Delta t
$$

where

$$
\Delta t=\text { time between hydro tests. }
$$

Thus, decreasing $\Delta t$ to decrease $P(F / E)$ may not be the correct approach because it could result in a larger value of $\phi(E)$, or there may be a value of $\Delta t$ that results in a maximum value of $\phi(F)$, and this "optimum" value of $\Delta t$ could be a function of time. As an illustration, consider $\Delta t=3,2$, and 1 EFPY $(100 \mathrm{MW})$. At the times of the last hydro tests $[47,48$, and 49 EFPY(100 MW)], the frequencies of failure are

$$
\begin{aligned}
& \phi(F)_{(\Delta t=3)}=1.25 \times 10^{-6} / 3.0=4.2 \times 10^{-7} / E F P Y(100 M W) \\
& \phi(F)_{(\Delta t=2)}=8.8 \times 10^{-7} / 2.0=4.4 \times 10^{-7} \\
& \phi(F)_{(\Delta t=1)}=4.6 \times 10^{-7} / 1.0=4.6 \times 10^{-7},
\end{aligned}
$$

which are nearly the same even though the values of $P(F / E)$ are quite different.

For large enough values of $t$, or $\Delta R T_{N D T} \times t, P(F / E)$ tends to saturate, as mentioned earlier. Thus, with reference to Eq. (2), it is apparent that as time progresses $P(F / E)$ will achieve a maximum value and then approach zero (this is not true, of course, if the effect of hydro testing is not included in the evaluation). Because of this, the maximum value of $P(F / E)$ of interest is not necessarily at the time of the last hydro test.

The greater the dose rate, the greater the chance of the maximum value of $P(F / E)$ occurring before the last hydro test. For instance, suppose that as a result of a design change the dose rate, beginning at 26 EFPY(100 MW), were five times that 
used to obtain the $R=1$ curve (Fig. 1), in which case the $R=5$ curve would apply. For this case, $P(F / E)(H T)_{\max }=8.6 \times 10^{-6}$ (Fig. 3), it occurs at $38 \mathrm{EFPY}(100 \mathrm{MW})$, and the reduction factor is $4.5 \times 10^{-5}$ (curve, $t=47$ )/8.6 $\times 10^{-6}=5.2$.

Values of $P(F / E)(H T)_{\max }$ and the corresponding hydro-test times and $P(F / E)$ reduction factors are included in Table 2 for $R=1,2,5,10$, and 30 and for $\Delta t=1$ and 3 EFPY $(100 \mathrm{MW})$. It is of interest to note that $P(F / F)(H T)_{\max }$ is approximately directly proportional to $R$ and $\Delta t$, and the $P(F / E)$ reduction factor is approximately inversely proportional to $\Delta t$, which means that the frequency of failure $[\phi(F)]$ is not sensitive to $\Delta t$, as indicated earlier. It is also observed that for both values of $\Delta t$, the reduction factor is insensitive to $R$ for $R=1,2$, and 5 , but for the two larger values of $R$, there is a significant decrease in the factor.

Table 2. Summary of $P(F / E)(H T)_{\max }$ and corresponding hydro-test times and $P(F / E)$ reduction factors for $R=1,2,5,10$, and 30 , and $\Delta t=1$ and 3 EFPY $(100 \mathrm{MW})$

\begin{tabular}{c|c|c|c|c|c|c}
\hline \multirow{2}{*}{$R^{a}$} & \multicolumn{2}{|c|}{$P(F / E)(H T)_{\max }^{\mathrm{b}}$} & \multicolumn{2}{c|}{$t(H T)$} & \multicolumn{2}{c}{$P(F / E)(H T, t=50-\Delta t) / P(F / E)(H T)_{\max }{ }^{\mathrm{c}}$} \\
\cline { 2 - 7 } & $\Delta t=1^{\mathrm{d}}$ & $\Delta t=3^{\mathrm{d}}$ & $\Delta t=1$ & $\Delta t=3$ & $\Delta t=1$ & $\Delta t=3$ \\
\hline 1 & $4.5 \times 10^{-7}$ & $1.3 \times 10^{-6}$ & 49 & 47 & 15.3 & 4.8 \\
\hline 2 & $1.2 \times 10^{-6}$ & $3.2 \times 10^{-6}$ & 49 & 47 & 15.8 & 5.2 \\
\hline 5 & $2.9 \times 10^{-6}$ & $8.6 \times 10^{-6}$ & 37 & 38 & 16.0 & 5.2 \\
\hline 10 & $5.8 \times 10^{-6}$ & $1.7 \times 10^{-5}$ & 31 & 32 & 9.2 & 3.2 \\
\hline 30 & $1.7 \times 10^{-5}$ & $4.1 \times 10^{-5}$ & 28 & 29 & 3.3 & 1.4 \\
\hline
\end{tabular}

${ }^{\mathrm{a}} R=\Delta R \dot{T}_{N D T}$ relative to the effective value used for the present beam-tube-facility design.

${ }^{\mathrm{b}} P(F / E)(H T)_{\max }=P(F / E)(H T)$ at time of but prior to hydro test, accounting for $H T$ benefit. ${ }^{c} P(F / E)(H T, t=50-\Delta t)=P(F / E)(H T)$ at time of last hydro test, not accounting for $H T$ benefit. ${ }^{d} \Delta t=$ time between hydro tests. 


\subsection{Probability of Failure for Emergency/Faulted Conditions}

The effect of the hydro test on the probability of failure for emergency/faulted conditions $[P(F / E)(E / F)]$ tends to be greater than the effect on $P(F / E)(H T)$. For instance, with reference to the $R=1 P(F / E)(H T)$ and $P(H / T)(E / F)$ curves in Fig. 4, if a hydro test is conducted at $26 \mathrm{EFPY}(100 \mathrm{MW})$, the probability of failure is reduced to zero for both the $H T$ and $E / F$ conditions. Mathematically [Eq. (2)], $P(F / E)(E / F)$ becomes less than zero because the same value of $P(F / E)=5 \times 10^{-7}$ is subtracted from both curves, in which case $P(F / E)(E / F)$ does not increase to zero until $t \cong 35$ EFPY $(100 \mathrm{MW})$, the time at which $P(F / E)(E / F)=P(F / E)(H T, t=26)$. Thus, if $\Delta t \leq(35$ - 26) $=9 \operatorname{EFPY}(100 \mathrm{MW}), P(F / E)(E / F)=0$ for $t=26$ to $35 \operatorname{EFPY}(100 \mathrm{MW})$ [a negative value of $P(F / E)$ from Eq. (2) implies zero probability of course]. Each time a hydro test is conducted, the $\Delta t$ required for $P(F / E)(E / F)=0$ increases. Thus, if $\Delta t$ $=3.0 \mathrm{EFPY}(100 \mathrm{MW}), P(F / E)(E / F)$ will always be zero.

As $R$ is increased, the time required for $P(F / E)(E / F)$ to reach zero decreases. Thus, there is some value of $R$ above which a specified value of $\Delta t$ will not result in $P(F / E)(E / F)_{\max }=0$ for all times. For instance, suppose, with reference to Fig. 4 , that $R=5$. The corresponding value of $\Delta t$ for $P(F / E)(E / F)_{\max }=0$ is $28.0-26.0=2.0$ EFPY (100 MW). Thus, if the specified value of $\Delta t$ is 3.0 EFPY $(100 \mathrm{MW})$, $P\left(F / E(E / F)_{\max }\right.$ will be greater than zero from $t=28$ to $29 \mathrm{EFPY}(100 \mathrm{MW})$. After 29 $\operatorname{EFPY}(100 \mathrm{MW})$, however, $P(F / E)(E / F)_{\max }=0$ for all times.

\section{DISCUSSION, SUMMARY, AND CONCLUSIONS}

The benefit of hydro testing in reducing the calculated probability of vessel failure was not included in previous studies for the HFIR vessel, ${ }^{1,2,3,4}$ but the effect can be significant, as indicated by this report. For the proposed vessel life extension period of 26 to 50 EFPY ( $100 \mathrm{MW})$ and the present experimental-facilities configuration, it is not necessary to include the effect of hydro testing in the calculation of the probability of failure in order to satisfy the related criteria. Doing so, however, reduces $\phi(F)(H T)$ by a factor of 4.8 and reduces $\phi(F)(E / F)$ to zero. 
Proposed design changes that result in larger-diameter beam tubes will increase the dose rate in the beam-tube nozzles and nozzle welds, increasing the calculated probability of vessel failure. For this case, it may be beneficial to include the effect of hydro testing in the calculation of the probability of failure. For the presently specified time between hydro tests [3.0 EFPY $(100 \mathrm{MW})]$ and for dose rates up to at least 5 times those associated with the present design, the $P(F / E)(H T)$ reduction factor is 5 . For dose rates as much as 10 and more greater than at present, the reduction factor is much less. If the dose rate is as much as 30 times the present value, the $P(F / E)(H T)$ reduction factor is only 1.4 .

Increasing the frequency of hydro testing increases the $P(F / E)$ reduction factor, and the increase is nearly proportional to the increase in frequency. However, for the hydro-test condition, for which the frequency of the loading event is equal to the frequency of hydro testing, the calculated frequency of failure, which is the product of $P(F / E)$ and the frequency of the loading event, does not change significantly. Of course, if there were a limit on $P(F / E)$ and not on $\phi(F)$, increasing the frequency of hydro testing would certainly be beneficial.

The report was completed in January 1997 and reflects the analytical and physical models and the criteria in use at that time. Since then, the models have been improved and the criteria modified, resulting in different calculated probabilities and different sensitivities. Even so, the concept of reducing the calculated probability of failure by including the effect of hydro testing in the analytical model remains valid. An up-to-date quantitative evaluation for HFIR is included in Ref. 11.

\section{REFERENCES}

1. R. D. Cheverton, J. G. Merkle, and R. K. Nanstad, Evaluation of HFIR Pressure-Vessel Integrity Considering Radiation Embrittlement, Oak Ridge National Laboratory, ORNL/TM-10444, April 1988. 
2. R. D. Cheverton, An Evaluation of Life Extension of the HFIR Pressure Vessel, Oak Ridge National Laboratory, ORNL/TM-12877, December 1994.

3. R. D. Cheverton, An Evaluation of Life Extension of the HFIR Pressure Vessel, Supplement 1, Oak Ridge National Laboratory, ORNLTM-12877S1, August 1996.

4. R. D. Cheverton and T. L. Dickson, HFIR Vessel Probabilistic FractureMechanics Analysis, Oak Ridge National Laboratory, ORNLTM-13303, in preparation, January 1997.

5. Personal Communication with J. R. Inger, Oak Ridge National Laboratory, November 1996.

6. Personal Communication with J. V. Pace, III, Oak Ridge National Laboratory, November 1996.

7. T. L. Dickson, FAVOR, Oak Ridge National Laboratory, ORNL/NRC/LTR-941, February 1994.

8. T. U. Marston, Ed., Flaw Evaluation Procedures: ASME Section XI, EPRI NP719-SR, Electric Power Research Institute, Palo Alto, CA, August 1978, including corrections dated April 14, 1980.

9. R. D. Cheverton and R. K. Nanstad, Evaluation of HFIR Vessel Surveillance Data and Hydro-Test Conditions, Oak Ridge National Laboratory, ORNL/TM12758, August 1994.

10. U. S. Nuclear Regulatory Commission, Radiation Embrittlement of Reactor Vessel Materials, Regulatory Guide 1.99, Rev. 2, May 1988. 
ORNL/TM-13376

11. R. D. Cheverton and T. L. Dickson, HFIR Vessel Life Extension with Enlarged HB-2 and HB-3 Beam Tubes, Oak Ridge National Laboratory, ORNL/TM13685, December 1998. 
ORNL/TM-13376

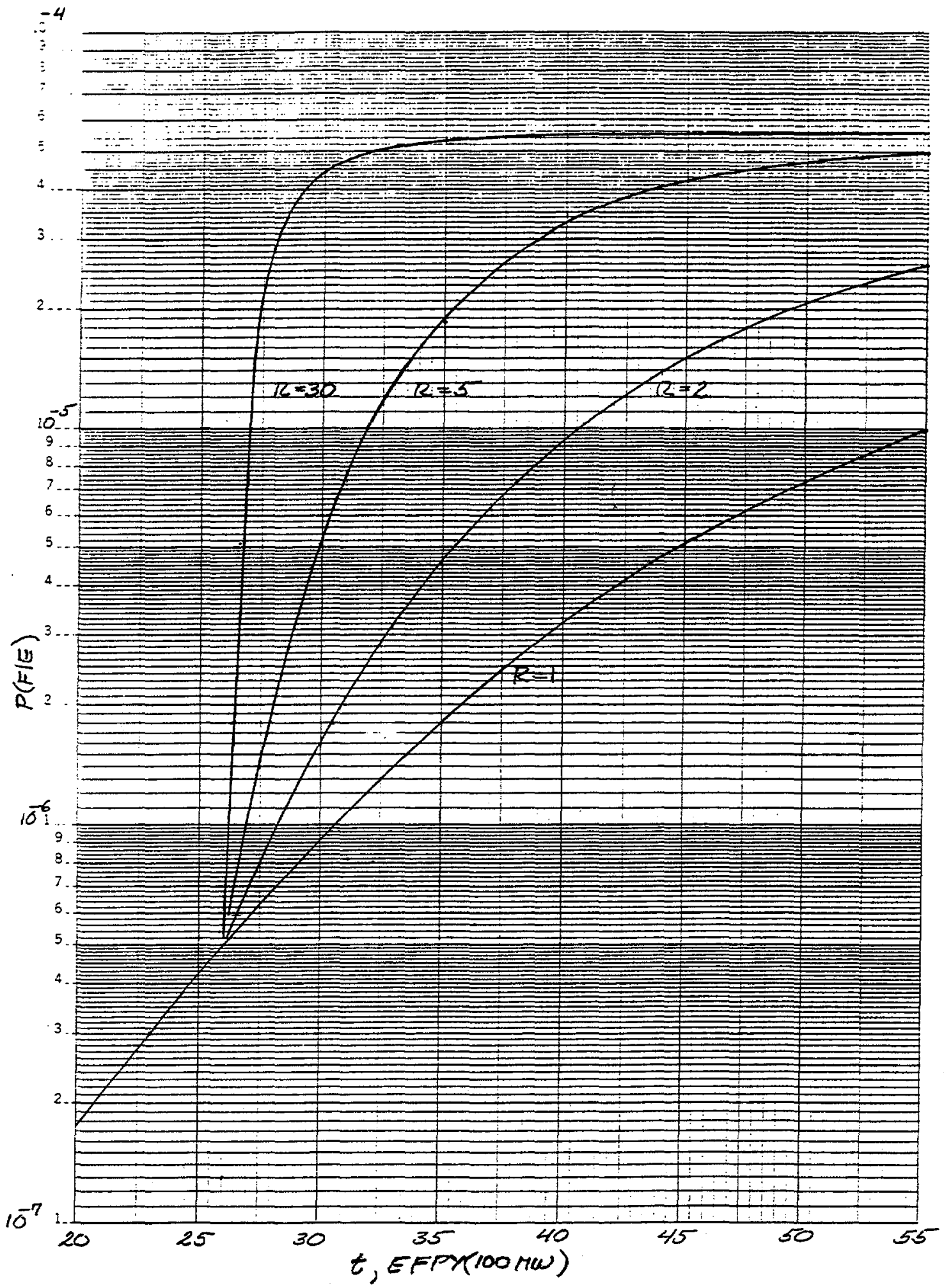

Fig. 1. $P(F \mid E)(H T)$ vs $t$ for several relative dose rates $(R)$ and for $p(H T)=850 \mathrm{psi}$ and $T_{v}(H T)=85^{\circ} \mathrm{F}(R=1$ pertains to present design $)$. 


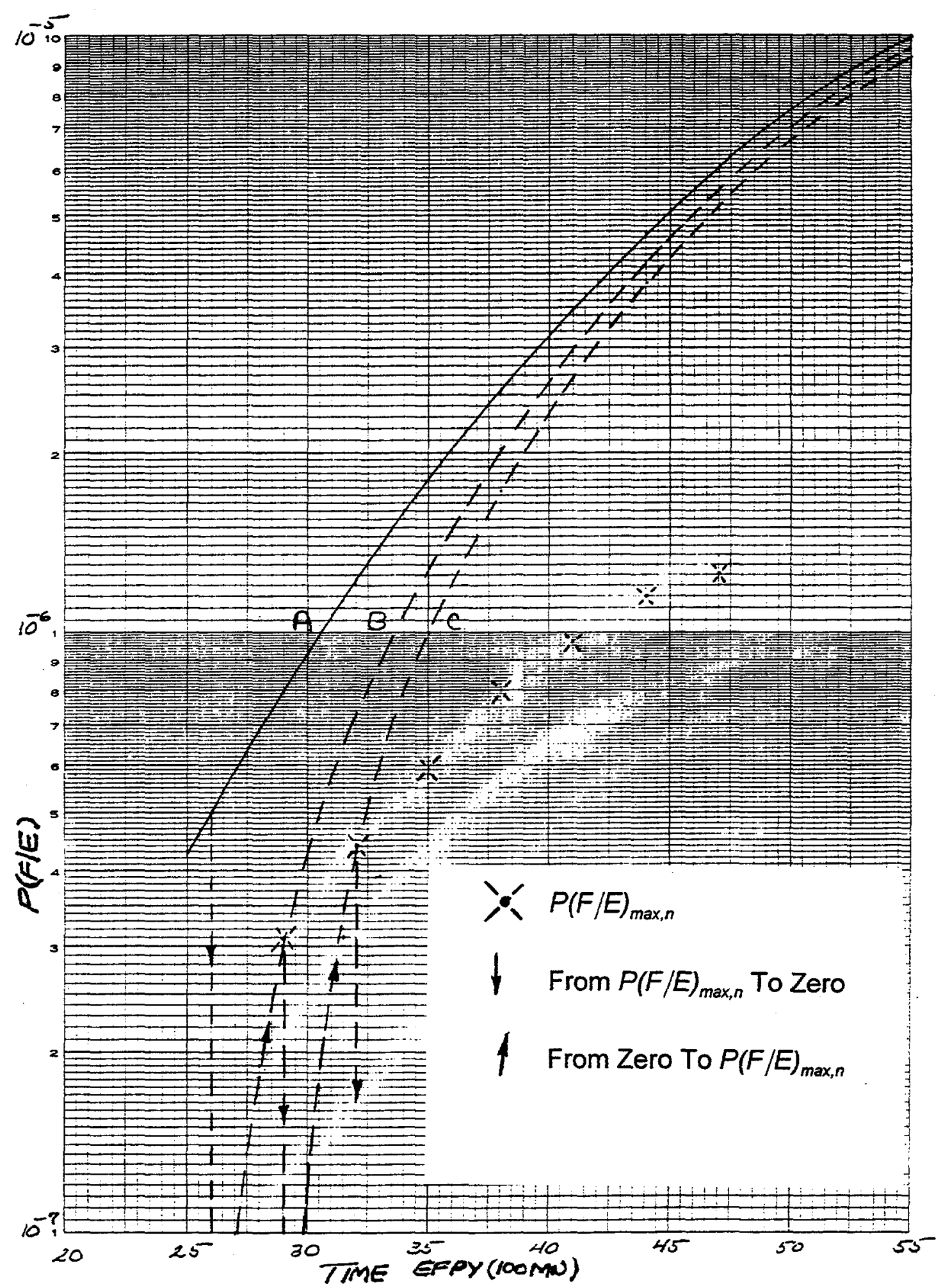

Fig. 2. $P(F / E)(H T)$ vs $t$ for $p(H T)=850$ psi and $T_{v}(H T)=85^{\circ} \mathrm{F}$, indicating beneficial effect of hydro testing for $\Delta t=3$ EFPY(100 MW). 
ORNL/TM-13376

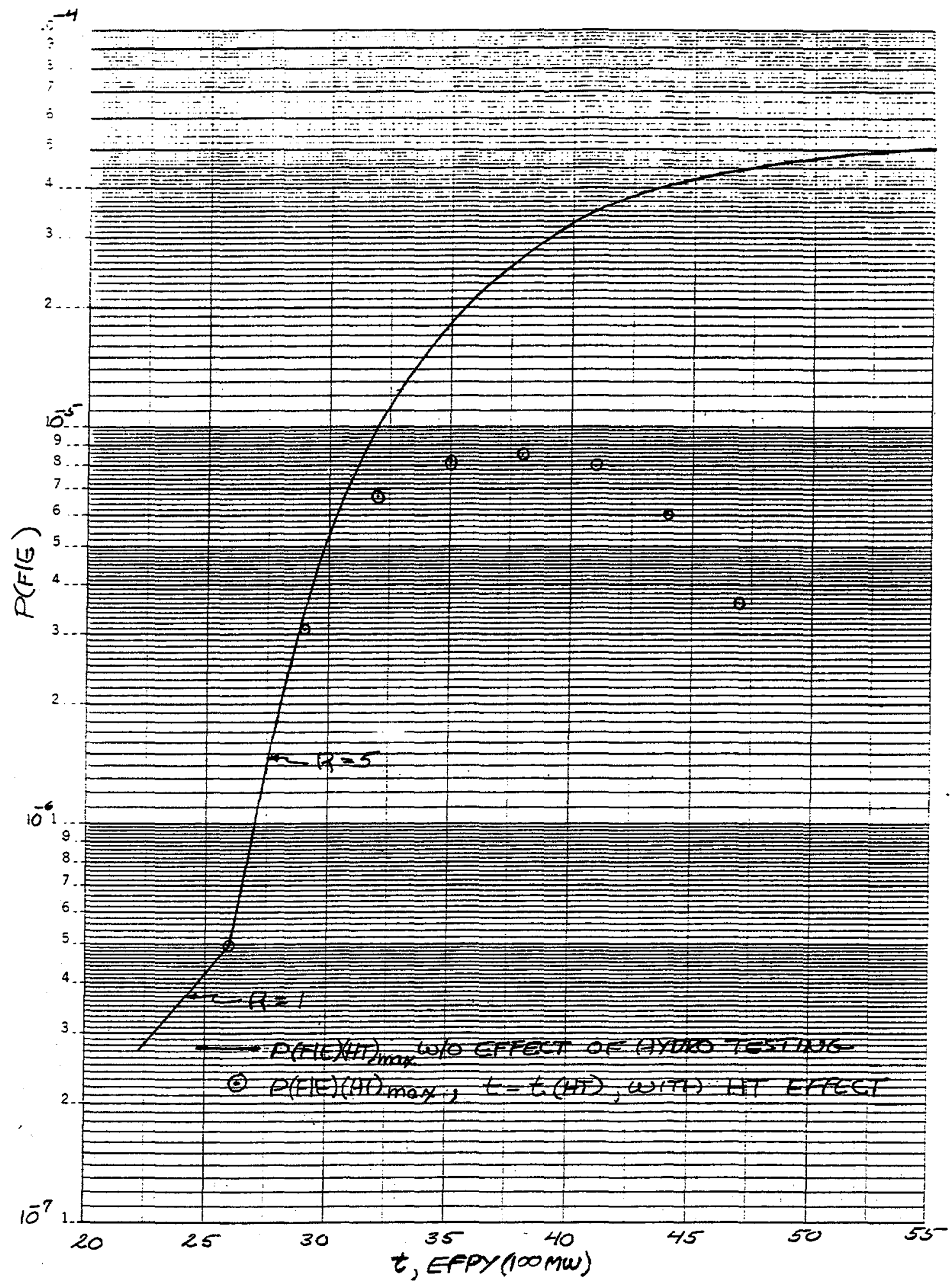

Fig. 3. $P(F \mid E)(H T)$ vs $t$, w/o effect of hydro testing, and $P(F \mid E)_{\max }$, with effect

$$
\text { [ } \Delta t=3 \mathrm{EFPY}(100 \mathrm{MW}), R=5]
$$


ORNL/TM-13376

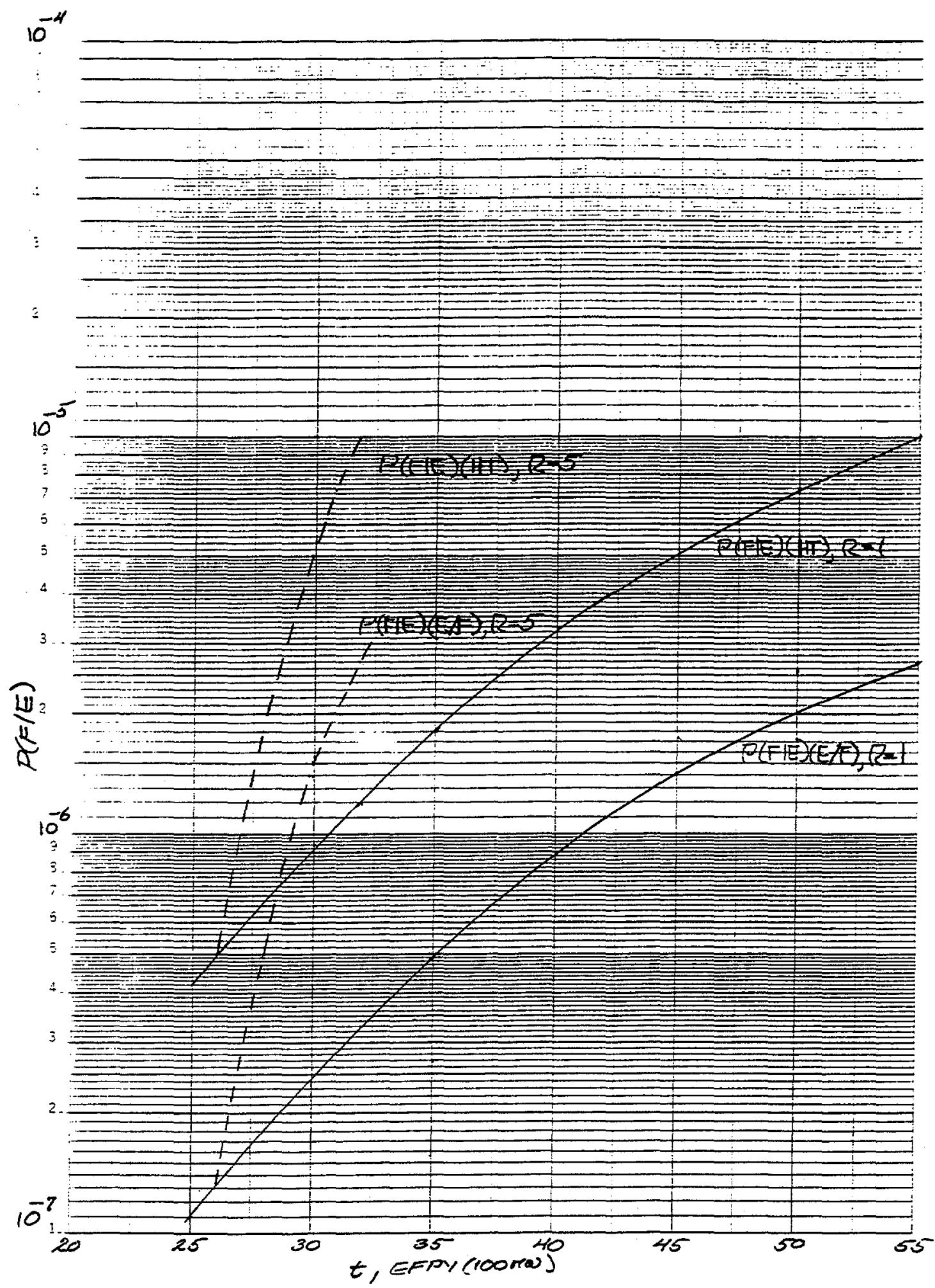

Fig. 4. $P(F \mid E)(H T)$ and $P(F \mid E)(E / F)$ vs $t$ for $R=1$ and 5 . 


\section{INTERNAL DISTRIBUTION}

$\begin{array}{llll}\text { 1. } & \text { S. E. Burnette } & 32 . & \text { M. A. Linn } \\ 2 . & \text { S. J. Chang } & 33 . & \text { R. S. McKeehan } \\ 3-7 . & \text { R. D. Cheverton } & 34 . & \text { J. G. Merkle } \\ 8 . & \text { D. H. Cook } & 35 . & \text { R. K. Nanstad } \\ 9 . & \text { R. E. Daniels } & 36 . & \text { J. V. Pace III } \\ \text { 10. } & \text { T. L. Dickson } & 37 . & \text { L. D. Proctor } \\ \text { 11. } & \text { H. R. Fair } & 38 . & \text { R. B. Rothrock } \\ \text { 12. } & \text { M. B. Farrar } & 39 . & \text { R. M. Stinnett } \\ \text { 13. } & \text { G. F. Flanagan } & 40 . & \text { E. L. Watkins III } \\ \text { 14. } & \text { M. L. Gildner } & 41 . & \text { T. Yahr } \\ \text { 15. } & \text { R. E. Hale } & 42 . & \text { RRD-DCC } \\ \text { 16. } & \text { R. W. Hobbs } & 43 . & \text { Central Research Library } \\ \text { 17-27. } & \text { J.R. Inger } & 44 . & \text { Document Reference } \\ 28 . & \text { S. K. Iskander } & & \text { Section } \\ 29 . & \text { M. W. Kohring } & 45-46 . & \text { Laboratory Records } \\ 31 . & \text { J. E. Lee } & 47 . & \text { Laboratory Records (RC) }\end{array}$

\section{EXTERNAL DISTRIBUTION}

48. E. G. Tourigny, Office of Nuclear Energy, NE-40-GTN, Department of Energy, Germantown, MD 20874-1290.

49. E. G. Cumesty, ORNL. Site Manager, Department of Energy, Oak Ridge National Laboratory, Oak Ridge, TN 37831-6269.

50-51. Office of Scientific and Technical Information, Post Office Box 62, Oak Ridge, TN 37831. 